\title{
Spontaneous Deposition of Cobalt Oxide Nanoplates for Application to Acetone Gas Sensors
}

\author{
Ahyeon Ma ${ }^{1,2, \dagger}$, Hyung Ju Park ${ }^{1, \dagger}$, Jong Hyeok Seo ${ }^{2}$, Jae Eun Lee ${ }^{1}$, Do Yeob Kim ${ }^{1}$, Hyung Kun Lee ${ }^{1}$, Ki \\ Min Nam ${ }^{2, *}$ Dae-Sik Lee ${ }^{1, *}$ \\ ${ }^{1}$ Electronics and Telecommunications Research Institute (ETRI), Daejeon 34129, Republic of Korea \\ 2 Department of Chemistry, Mokpo National University, 1666 Yeongsan-ro, Muan-gun, Jeonnam \\ 58554, Republic of Korea \\ namkimin@mokpo.ac.kr, dslee@etri.re.kr
}

\begin{abstract}
The development of sensing materials, which influence the practical gas sensing performance, is critically important for the further evolution of semiconducting metal oxide gas sensor. Especially, cobalt oxides have attracted great interest in their potential applications as solid-state sensors because of their chemical stability and semiconducting properties. In this study, we are reporting the spontaneous deposition of $\mathrm{CO}_{3} \mathrm{O}_{4}$ nanoplates on interdigitated electrodes and its application to gas sensors. Inducing the phase transition of $h-\mathrm{CoO}$ to $\mathrm{Co}(\mathrm{OH})_{2}$ and consecutive thermal oxidation on silicon substrate results in efficient deposition between $\mathrm{CO}_{3} \mathrm{O}_{4}$ and the substrate without any additional deposition processes. The efficient deposition of $\mathrm{CO}_{3} \mathrm{O}_{4}$ nanoplates is applicable for acetone gas sensors.
\end{abstract}

Key words: $\mathrm{CoO}, \mathrm{Co}(\mathrm{OH})_{2}, \mathrm{Co}_{3} \mathrm{O}_{4}$, Phase transition, Gas sensor

\section{Introduction}

Cobaltous oxide $(\mathrm{CoO})$ typically crystallizes in two crystal phases, cubic rocksalt $\mathrm{CoO}$ with octahedral $\mathrm{Co}^{2+}$ and hexagonal wurtzite $\mathrm{CoO}$ with tetrahedral $\mathrm{Co}^{2+}$ ions.[1] Especially, the meta-stable $h$-CoO phase has attracted great interest because it involves various fundamental themes of materials chemistry, such as phase transitions, and distinctive physicochemical properties.[2] In addition to $\mathrm{CoO}$, spinel $\mathrm{CO}_{3} \mathrm{O}_{4}$ has also been a central issue because of its superior catalytic, magnetic, and electrochemical features.[1] The $\mathrm{CO}_{3} \mathrm{O}_{4}$ nanostructures have recently been used for solid-state gas sensors, where the sensing characteristics are mainly influenced by the morphology and porosity of the nanostructures.[3]

In the present study, we report the spontaneous deposition of $\mathrm{CO}_{3} \mathrm{O}_{4}$ nanoplates on an electrical device. Inducing the phase transition of $h-\mathrm{CoO}$ to $\mathrm{Co}(\mathrm{OH})_{2}$ and consecutive annealing process on the electrical devices results in efficient deposition between $\mathrm{CO}_{3} \mathrm{O}_{4}$ and the substrate without any additional deposition processes. This finding demonstrates the phase transition of nanomaterials can be an effective way of designing high performance gas sensors, and also provides a new insight into gas sensor fabrication without complicated processes.[4]

\section{Experimental Details}

The $h$-CoO nanocrystals were obtained by a solvothermal reaction.[1] When the $h-\mathrm{CoO}$ nanocrystals were spin-coated onto interdigitated electrodes, and then deionized water was added, the conversion from $h$-CoO to $\beta-\mathrm{Co}(\mathrm{OH})_{2}$ took place at room temperature.[5] Consecutively, the $\beta-\mathrm{Co}(\mathrm{OH})_{2}$ nanoplates were annealed at $300{ }^{\circ} \mathrm{C}$ for $2 \mathrm{~h}$ under an atmospheric pressure of air to yield spinel $\mathrm{Co}_{3} \mathrm{O}_{4}$ nanoplates. And the gas sensing properties of synthesized $\mathrm{Co}_{3} \mathrm{O}_{4}$ nanoplates were measured using a computer-controlled characterization system which included a

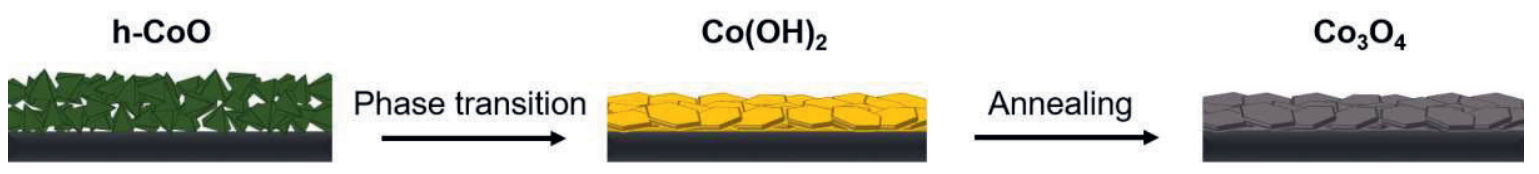

Fig. 1. Schematic illustration of the synthesis of $\mathrm{Co}_{3} \mathrm{O}_{4}$ nanoplates on the silicon substrate. 
temperature-controlled steel chamber, mass flow controllers (MFCs), and a digital multimeter.[3]

\section{Results and Discussion}

(a)

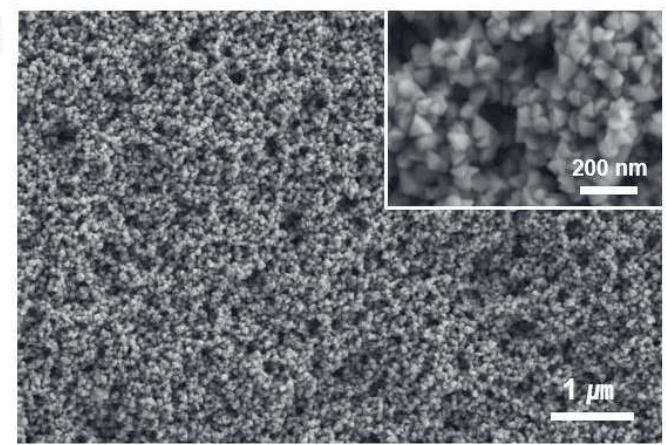

(b)

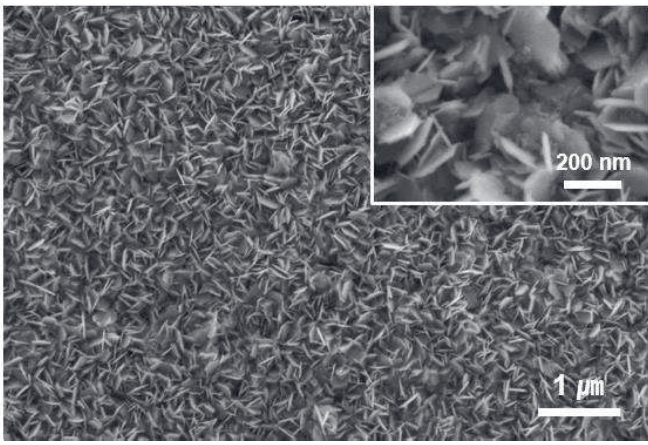

(c)

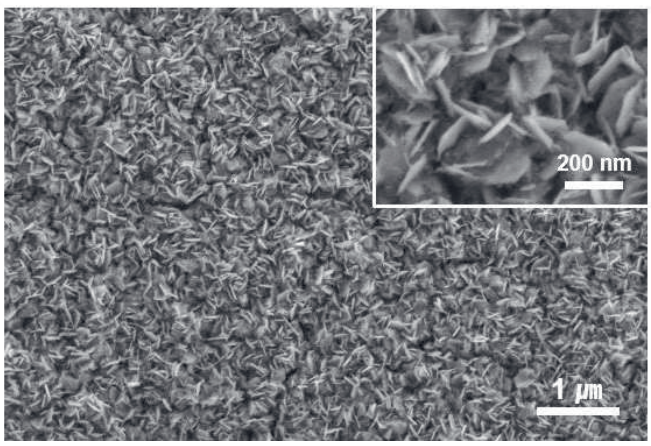

Fig. 2. SEM images of (a) h-CoO pyramids, (b) $\mathrm{Co}(\mathrm{OH})_{2}$ nanoplates, (C) $\mathrm{CO}_{3} \mathrm{O}_{4}$ nanoplates on the silicon substrate.

The synthetic approach of $\mathrm{Co}_{3} \mathrm{O}_{4}$ nanoplates involved three sequential reactions; preparation of $h-\mathrm{CoO}$, phase transition to $\mathrm{Co}(\mathrm{OH})_{2}$, and oxidation (Fig. 1). Figure 2a shows SEM image of the $h$-CoO pyramids which have an average side edge length of $40 \pm 6.4 \mathrm{~nm}$. The direct addition of water drives the phase transition of $h-\mathrm{CoO}$ to $\mathrm{Co}(\mathrm{OH})_{2}$ on the silicon substrate. The $\mathrm{Co}(\mathrm{OH})_{2}$ nanocrystals exhibited a hexagonal plate shape with an average side edge length of $70 \pm 11 \mathrm{~nm}$ (Fig. 2b). Consecutive dehydration and oxidation of $\mathrm{Co}(\mathrm{OH})_{2}$ yielded $\mathrm{CO}_{3} \mathrm{O}_{4}$ nanocrystals with the shape identical to the original one of the hexagonal nanoplate (Fig. 2c). The plate-shaped morphology of the as grown $\mathrm{Co}_{3} \mathrm{O}_{4}$ can be clearly observed in the SEM images (Fig. 2c), indicating that efficient deposition occurred on the electrical devices via phase transitions without any additional deposition processes.

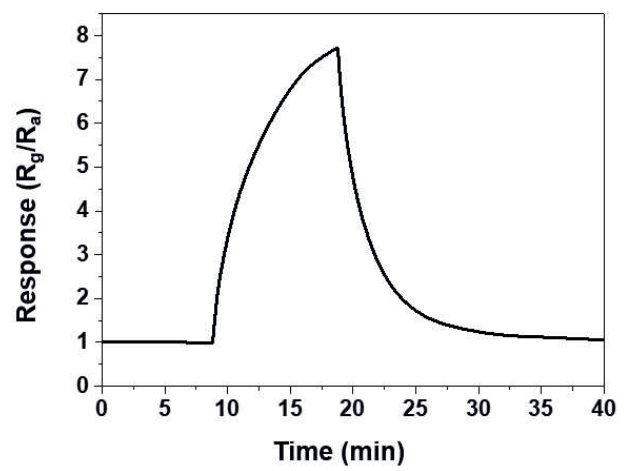

Fig. 3. Response curve of $\mathrm{CO}_{3} \mathrm{O}_{4}$ nanoplate gas sensor to $1 \mathrm{ppm}$ acetone at $200^{\circ} \mathrm{C}$.

Gas-sensing properties of $\mathrm{CO}_{3} \mathrm{O}_{4}$ nanoplates were investigated using a characterization system with a temperature-controlled hot chuck in a water-cooled steel chamber. The gas response is defined as the ratio of resistance, $R$ $=R_{g} / R_{a}$, where $R_{a}$ and $R_{g}$ are the resistance in an air and in a gas atmosphere, respectively. The real-time gas response of $\mathrm{CO}_{3} \mathrm{O}_{4}$ nanoplates were measured under the standard condition with the exposure of $1 \mathrm{ppm}$ acetone gas at $200{ }^{\circ} \mathrm{C}$ (Fig. 3). The $\mathrm{Co}_{3} \mathrm{O}_{4}$ nanoplates exhibited quite higher gas sensitivity, and better stability than previous results.[3]

\section{Acknowledgement}

This research was supported by the National Research Foundation of Korea under research projects. (NRF-2017M3A9F1033056)

\section{References}

[1] K. M. Nam, J. H. Shim, D.-W. Han, H. S. Kwon, Y. Li, H. Song, W. S. Seo, J. T. Park, Chem. Mater., 22, 4446-4454 (2010); doi: 10.1021/cm101138h

[2] K. M. Nam, W. S. Seo, H. Song, J. T. Park, NPG Asia Mater., 9, e364 (2017); doi: 10.1038/am.2017.38

[3] J. Y. Kim, N.-J. Choi, H. J. Park, J. Kim, D.-S. Lee, H. Song, J. Phys. Chem. C, 5118, 25994-26002 (2014); doi: 10.1021/jp505791v

[4] S.F. Shen, M.L.Xu, D. Bao, H.B. Pan, Applied Surface Science, 396, 327-332 (2017); doi:10.1016/j.apsusc.2016.10.147

[5] K. Y. Jang, G. Park, K. H. Oh, J. H. Seo, and K. N. Nam, Chem. Commun., 53, 4120-4123 (2017); doi: $10.1039 / C 7 C C 00388 A$ 